\title{
From the Editor-in-Chief's Desk: The Value of Reflexivity
}

\author{
Margaret H. Vickers
}

Published online: 1 October 2010

(C) Springer Science+Business Media, LLC 2010

I commenced the September 2010 issue of Employee Responsibilities and Rights Journal with an editorial about the value of critical reflection. I urged readers to find ways to encourage enhanced understanding of employee and employer rights and responsibilities via turning their attention to critical reflection upon the challenges and tensions that inevitably arise in our workplaces. I reminded readers that reflection is a modernist notion incorporating the mirror image. It is also a process that assumes there will be an original that we can think about, categorize, and explain. Reflection, then, is concerned with simplifying our thinking about experience by searching for patterns, logic, and order (Cunliffe 2002), and proactive critical reflection works toward surfacing and critiquing any tacit or taken-for-granted assumptions and beliefs around those notions of order and logic, and should also include thoughts and feelings (Boud et al. 1985; Gray 2007). I concluded by pointing out that critical reflection can provide us with a useful bridge between experience and learning about employee and employer rights and responsibilities.

However, we need also to consider the importance of critical reflexivity when thinking about employees, employers, and their respective rights and responsibilities. If reflection is a modernist process of ordering and simplification, reflexivity is about complexifying our thinking to deliberately expose contradictions, doubts, dilemmas, and possibilities (Cunliffe 2002). What is helpful about reflexivity, especially when dealing with the challenges enveloping employee rights and responsibilities, is that the reflexive consideration of any story or circumstance requires recognition of different contents, audiences, experiences, contexts, and perspectives (Ramsey 2005). By not reducing these multiple perspectives down to one story - the "correct" one - is how we can learn from them and find better, more ethical and responsible resolutions. Reflexivity also embraces subjective understandings, enabling a more critical consideration of one's values and the effects those values and their corresponding actions might have on other people, especially within our workplaces (Palmer and Dunford 1996; Gray 2007; Cunliffe 2002). Reflexive thinking enables us to open up spaces for alternative views, allowing us to find the voice of others. Doing this enables people in organizations more easily to recognize differences and conflicts that arise, and to respond

M. H. Vickers $(\bowtie)$

University of Western Sydney, Sydney, NSW, Australia

e-mail: M.Vickers@uws.edu.au 
more proactively to them. It is this recognition of the value of a plurality of views, perspectives, and responses to employee rights and responsibilities that I highlight as being so useful here.

Reflexive dialogues also enable the critique of previously uncontested assumptions and beliefs and other sources of unhelpful or taken-for-granted "truths" in organizational life (Gray 2007). Engaging with reflexive dialogues can offer a means of exposing and recognizing diverse values, beliefs, assumptions, and mental models in ways that might assist organizations trying to create supportive and ethical responses. Reflexive dialogue also offers an authentic and informed approach to finding a solution or an outcome that is likely to be acceptable (in sum or in part) to more of the stakeholders concerned with or affected by the problem under review because it is an approach recognizing multiple perspectives and varied sources of input. For instance, issues that might be considered unimportant when heard only from the original teller's perspective might assume considerably more importance when told by another, or others, and from another perspective (Ramsey 2005). When we discuss issues with critical reflexivity, we encourage organizational members to question their own existing assumptions and beliefs, as well as those of others, and the impact of those beliefs and actions on the organization, their colleagues, and the community at large (Cunliffe 2009). This then forms a more authentic dialogue - with all its foibles, nerves, and uncertainties - that can offer more proactive and positive responses to sensitive and challenging situations facing both employers and employees.

Reflexive processes can assist management understanding and self-knowledge (Gray 2007); it is noted, for instance, that more authentic leadership capabilities are enabled by more open, honest dialogue among organizational members (Mazutis and Slawinski 2008). Reflexive dialogue shows actors shaping and being shaped by their experiences, reconsidering fundamental assumptions, values, and ways of interacting, while questioning their core beliefs, understandings of events, and how these understandings might have contributed to their responses (Cunliffe 2009). The authentic dialogue that comes from the process of reflexivity allows barriers to learning to be addressed and overcome more easily, the detection and correction of errors to take place, and for organizational members to become more self-aware, as well as more open, honest, and balanced in their accounts. They will also be better able to monitor their values and beliefs, if they are endeavoring to communicate them transparently (Mazutis and Slawinski 2008).

Organizational actors should be encouraged to engage in reflexive dialogues when considering the organizational challenges they might face, and as an aid to learning about employee responsibilities and rights in our places of work. I encourage readers of this journal to think also about reflexivity when undertaking their research. I would certainly welcome anyone interested in hosting a special issue around this or any other topic of relevance to employee responsibilities and rights. As 2010 draws to a close, I am excited about the future of the journal moving forward. Employee Responsibilities and Rights Journal continues to showcase exciting, leading-edge, international research that canvasses issues of concern to both employers and employees negotiating the often fraught path of employment responsibilities and rights. I take this opportunity to wish all of our readers, authors, referees, Editorial Board, and editorial management team the compliments of the season, and a safe and healthy new year for all.

We all look forward to your continuing contributions and support for Employee Responsibilities and Rights Journal in 2011. 


\section{References}

Boud, D., Keogh, R., \& Walker, D. (1985). What is reflection in learning? In D. Boud, R. Keogh, \& D. Walker (Eds.), Reflection: Turning experience into learning (pp. 7-17). London: Kogan Page.

Cunliffe, A. L. (2002). Reflexive dialogical practice in management learning. Management Learning, 33(1), $35-61$.

Cunliffe, A. L. (2009). The philosopher leader: on relationalism, ethics and reflexivity-A critical perspective to teaching leadership. Management Learning, 40(1), 87-101.

Gray, D. E. (2007). Facilitating management learning: developing critical reflection through reflective tools. Management Learning, 38(5), 495-517.

Mazutis, D., \& Slawinski, N. (2008). Leading organizational learning through authentic dialogue. Management Learning, 39(4), 437-456.

Palmer, I., \& Dunford, R. (1996). Conflicting uses of metaphors: reconceptualizing their use in the field of organizational change. Academy of Management Review, 21(3), 691-717.

Ramsey, C. (2005). Narrative: from learning in reflection to learning in performance. Management Learning, $36(2), 219-235$. 